\title{
ERANET-MED OPTIMED-WATER PROJECT: RESULTS ON SOIL MOISTURE MAPS OF SEMI-ARID ENVIRONMENT BY USING OPTICAL/MICROWAVE SATELLITE DATA
}

\author{
S. Paloscia ${ }^{1}$, G. Fontanelli ${ }^{1}$, S. Pettinato ${ }^{1}$, E.Santi ${ }^{1}$, G.Ramat ${ }^{1}$, \\ Emmanuel DaPonte ${ }^{2}$, M.M. Abdel-Wahab ${ }^{3}$, Y. H. Essa', A.A. Khalil ${ }^{4}$ M. Ouessar ${ }^{5}$, H. Dhaou', Z. Kassouk ${ }^{6}$, Z. L. Chabaane \\ ${ }^{1}$ IFAC-CNR (Italy), ${ }^{2}$ DLR (Germany), ${ }^{3}$ Cairo University (Egypt), ${ }^{4}$ CLAC-ARC (Egypt), ${ }^{5}$ IRA (Tunis), ${ }^{6}$ INAT (Tunis)
}

\begin{abstract}
This project deals with the implementation of an innovative water management system in Mediterranean countries (i.e. Tunisia and Egypt), which suffer from chronic water scarcity, together with two European countries (Germany and Italy). The consortium is developing and applying synergic methods and algorithms for investigating the water cycle, using remote sensing techniques.

The focus is on the use of satellite data (optical and microwave) for monitoring vegetation cover and water status along with soil moisture temporal evolutions in order to improve the knowledge of the water cycle in arid areas. Both local and regional monitoring are carried out in order to investigate different spatial scales.

The scope of the project is to propose practical and costeffective solutions for driving and updating a method for the sustainable use of water in agriculture.

First results on soil moisture mapping retrieved in Tunisia using an Artificial Neural Network (ANN) based algorithm is presented in this paper.
\end{abstract}

Index Terms - soil moisture maps, optical sensors, SAR, artificial neural networks

\section{INTRODUCTION}

This project aims at overcoming the lack of local and regional information on the knowledge of the main parameters of water and carbon cycles (as soil moisture, vegetation biomass and crop water status) by using the potentials offered by new satellite systems in both microwave and optical domain and advanced modeling.

The goal of the project is the definition of an optimized management of water resources for cultivated lands on Egyptian Delta (Northern part) and Tunisian territory. This will be achieved by analyzing the available spatial and temporal data for the areas of interests, appropriately selected for this purpose. As such, an efficient water use, equitable distribution of water resources, community participation in decisions, and sustainable system operation over time can be supported.
First of all, we aim to localize different crop and irrigation techniques for the study regions. This information is required as a basis for further investigations and assessments.

Secondly, the water efficiency for different lands, crop types and irrigation systems will be assessed.

Afterwards, possible improvements in agricultural practice with respect to climate change scenarios and information on water efficiency will be determined by rating the outcome from the assessment.

\section{STUDY AREAS}

\subsection{Egypt}

The project implementation steps focus on the northern part of Egypt (Delta and coastal area: Lat. 29.5 -31.5 N; Lon. 25.5$32.2 \mathrm{E})$. The study region contains the most important agricultural area in Egypt, representing 55.5\% of the Egyptian cultivated areas as well one of most rainy locations in the country. The Nile Delta can be considered as problematic lands regarding their fine texture, poor drainage, as well as the intrusion of seawater into the groundwater table. Therefore, these soils are threatened by drought, waterlogging, soil compaction, salinization, and in general land degradation processes more than any other alluvial soils.

\subsection{Tunisia}

\subsubsection{Medenine area (IRA)}

One of the Tunisian test areas is located in the province of Medenine, in southeast Tunisia between the latitude $37^{\circ} 10^{\prime} \mathrm{N}$ and $37^{\circ} 50^{\prime} \mathrm{N}$ and the longitude $8^{\circ} 50^{\prime} \mathrm{E}$ and $9^{\circ} 20^{\prime} \mathrm{E}$. The Province of Medenine is in a strategic position in the middle of the Mediterranean basin. It covers an area of $9167 \mathrm{~km}^{2}$ and has a population of 498,785 .

The province of Medenine is characterized by an arid climate with an extreme irregularity owing to the fact that it is subjected to two opposite centres of weather actions: (i) dry and hot Saharan air coming from the southwest of the study area (Dahar plateau) and (ii) Mediterranean climate, relatively wet and moderate from the Gulf of Gabes (Mediterranean Sea).

According to the $3^{\text {rd }}$ Technical Conference on Advanced Techniques of Inspection, NDT, and Monitoring Practices 
(INM 2017), the annual and seasonal temperatures increased significantly during the period 1951-2010 whereas precipitation shows a decreasing trend of $-4 \mathrm{~mm} /$ decade.

\subsubsection{The Merguellil Plain (INAT)}

The Merguellil River is the second main river in central Tunisia. The Merguellil basin has limited and fragile water resources and faces an increasing water demand (mainly for agriculture and drinking water), which leads to a groundwater overexploitation. Typical of the high pressure over Tunisian water resources, this region is considered by national authorities as a pilot for developing new integrated approaches for water resources management.

Irrigation is now widely spread all over the Merguelil plain and depends on groundwater resources. The main crops are cereals, olive trees, tomato, melon, watermelon, and chili. In the upper part of the basin, crops are more various and irrigation is less present.

\section{SATELLITE DATA}

Satellite data have been acquired on these test areas to monitoring the vegetation cover and in assessing the agricultural drought in the selected area.

The Moderate Resolution Imaging SpectroRadiometer (MODIS) instrument of Terra satellite has been used in measuring the Normalize difference vegetation index (NDVI) produced on 16-day intervals, at multiple spatial resolutions, which provide consistent spatial and temporal series of vegetation canopy greenness, composite properties of leaf area, chlorophyll, and canopy structure. In Egypt, MODIS images have been acquired for the months of January, July, and September, which represent the midseason months of winter, summer, and Nile seasons, respectively.

SAR satellite data coming from ESA Sentinel-1 (S-1) and ASI COSMO-SkyMed (CSK) have been collected on both study areas and used to fulfill the OPTIMED purposes. The wide coverage and the high temporal resolution of $\mathrm{C}$-band SAR data from Sentinel-1 are used for mapping and monitoring crop growth and soil moisture all over the test sites.

The used COSMO-SkyMed product (Stripmap HIMAGE) has a smaller swath with respect to Sentinel-1, but higher spatial resolution. Examples S-1 and CSK orbits and coverage on Nile Delta are shown in figure 1.

\section{SENSITIVITY TO SOIL MOISTURE}

In this paper, an attempt for estimating the soil moisture content (SMC) in the arid environment in Tunisia is presented. In countries characterized by arid and semi-arid climate it is very important to obtain reliable estimates of soil moisture evolution for water management purposes, in order to reduce water wastes and properly schedule agricultural practices. On the other hand, the retrieval of SMC is often hampered by the small humidity range (below 10\%). Therefore, a retrieval algorithm aiming at estimating the soil moisture and based on artificial neural networks (ANN) was implemented, using the data collected by the SAR sensor of Sentinel-1.

Taking advantage of the fast computation and high retrieval accuracy, ANN can generate reliable output maps of SMC starting from the complex SAR images and using little auxiliary information, as DEM, LIA, NDVI, and so on.

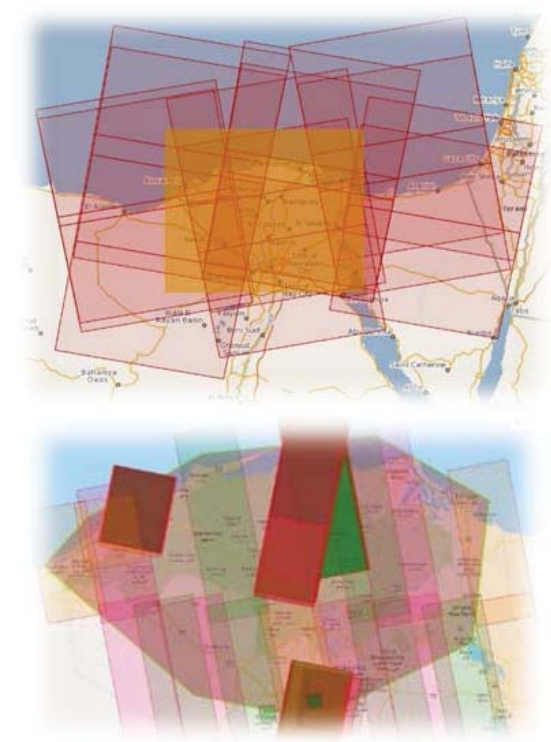

Figure 1. Examples of satellite orbits and coverage of S-1 (top) and CSK (bottom) on Nile Delta

The peculiar strategy adopted for the training, which has been obtained by combining satellite measurements with data simulated by electromagnetic model (based on the Integral Equation Model, IEM, by Fung 1994), made this algorithm robust and almost site independent (Paloscia et al. 2013, Santi et al. 2016).

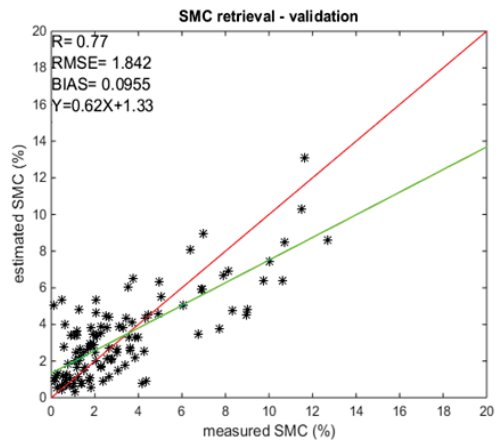

Figure 2. Validation of the ANN algorithm.

The obtained results demonstrated that ANN represent a powerful tool for estimating SMC, provided that they have been trained with consistent datasets, made up of both experimental and theoretical data. The relationship of the algorithm validation between the estimated and measured 
SMC showed correlation coefficient $\mathrm{R}=0.77$, and $\mathrm{RMSE}=1.84 \%$, in spite of the very low SMC values found in the area (figure 2).

A series of SMC maps of the area of Wadi Hallouf/Oum Zessar have been generated by using the ANN algorithm from all the available Sentinel-1 images, from November 2015 to April 2016, thus covering an entire seasonal cycle (figure 3) (Hachani et al. 2019).
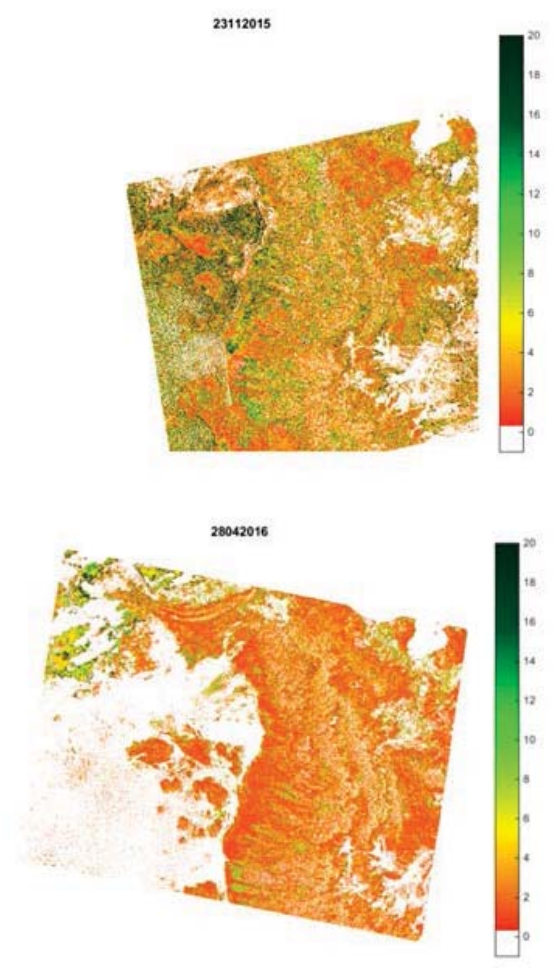

Figure 3. Two examples of SMC maps obtained through the ANN algorithm from Sentinel-1 images on Tunisia in November 23rd 2015, and April 28th 2016. Red ellipse represents the test area.

\section{CONCLUSIONS}

An overview of the Optimed-Water ERANET-MED project was presented in this paper along with an application of Artificial Neural Networks (ANN) techniques for retrieving SMC from satellite acquisition.

An ANN based algorithm has been developed and tuned for working with C-band SAR acquired from Sentinel-1. IEM forward electromagnetic model simulations have been considered for training the ANN. The results obtained from this algorithm show a good agreement between estimated and measured soil moisture, with high determination coefficients $(\mathrm{R}=0.77)$ and rather low $\mathrm{RMSE}=1.84 \%$. By considering the limited range of measured SMC (between 0 and 10-12\%), due to the arid conditions of the test area, the results can be considered encouraging.
The proposed method can be suggested as a valid tool for estimating soil moisture in arid countries in order to set up a drought early warning system and producing reliable and timely information for decision makers. This method should be further tested and validated in other semi-arid countries and I particular on the other study areas of the project.

\section{REFERENCES}

[1] Fung, A. K., 1994. Microwave scattering and emission models and their applications. Norwood, MA: Artech House Fung 1994

[2] Hachani A., M. Ouessar, S. Paloscia, E. Santi \& S. Pettinato (2019), Soil moisture retrieval from Sentinel-1 acquisitions in an arid environment in Tunisia: application of Artificial Neural Networks techniques, International Journal of Remote Sensing, 40:24, 9159-9180

[3] Paloscia S.; Pettinato S.; Santi E.; Notarnicola C.; Pasolli L.; Reppucci A., 2013. Soil moisture mapping using Sentinel-1 images: Algorithm and preliminary validation. Remote Sens. Environ. 134, 234-248.

[4] Santi, E., S. Paloscia, S. Pettinato, G. Fontanelli. Application of artificial neural networks for the soil moisture retrieval from active and passive microwave spaceborne sensors. Int. J. Appl. Earth Observ. Geoinf. 2016, Volume 48, Pages 61-73. http://dx.doi.org/10.1016/j.jag.2015.08.002. 